\title{
Novel Tocolytic Strategy: Modulating Cx43 Activity by S-Nitrosation $\$$
}

\author{
Scott D. Barnett, Hazik Asif, Mitchell Anderson, and lain L. O. Buxton \\ Department of Pharmacology, Myometrial Function Group, University of Nevada, Reno School of Medicine, Reno, NV \\ Received November 20, 2020; accepted December 23, 2020
}

\begin{abstract}
Currently available tocolytics are ineffective at significantly delaying preterm birth. This is due in part to our failure to better understand the mechanisms that drive spontaneous preterm labor (sPTL). Cyclic nucleotides are not the primary contributors to myometrial quiescence, but instead nitric oxide (NO)-mediated protein S-nitrosation (SNO) is integral to the relaxation of the tissue. Connexin-43 (Cx43), a myometrial "contractile-associated protein" that functions as either a gap junction channel or an hemichannel $(\mathrm{HC})$, was the focus of this study. Protein analysis determined that $\mathrm{Cx} 43$ is downregulated in SPTL myometrium. Furthermore, Cx43 is S-nitrosated by NO, which correlates with an increase of phosphorylated Cx43 at serine 368 (Cx43-pS368 -gap junction inhibition) as well as an increase in the $\mathrm{HC}$ openstate probability (quiescence). Pharmacologic inhibition of $\mathrm{Cx} 43$ with $18 \beta$-glycyrrhetinic acid (18 $\beta$-GA) exhibits a negative inotropic effect on the myometrium in a dose-dependent manner, as does administration of nebivolol, an NO synthase activator that increases total protein SNOs. When $18 \beta-\mathrm{GA}$ and nebivolol were coadministered at their $\mathrm{IC}_{50}$ values, the effect on
\end{abstract}

contractile dynamics was additive and all but eliminated contractions. The development of new tocolytics demands a better understanding of the underlying mechanisms of SPTL. Here it has been shown that $18 \beta-\mathrm{GA}$ and nebivolol leverage dysregulated pathways in the myometrium, resulting in a novel approach for the treatment of SPTL.

\section{SIGNIFICANCE STATEMENT}

Although there are many known causes of preterm labor (PTL), the mechanisms of "spontaneous" PTL (sPTL) remain obfuscated, which is why treating this condition is so challenging. Here we have identified that connexin-43 (Cx43), an important contractile-associated protein, is dysregulated in SPTL myometrium and that the pharmacologic inhibition of $\mathrm{C} \times 43$ and its $S$-nitrosation with $18 \beta$-glycyrrhetinic acid and nebivolol, respectively, significantly blunts contraction in human myometrial tissue, presenting a novel approach to tocolysis that leverages maladjusted pathways in women who experience SPTL.

\section{Introduction}

Seventy-five years of tocolytic development (Vanbésien and Eichner, 1956) have produced little in terms of effective therapies to halt preterm labor (PTL) or delay preterm birth (PTB) (World Health Organization, 2015). This is concerning not only for the more than 15 million infants born prematurely each year, many of whom will experience lifelong health complications, such as chronic lung and cardiovascular disease, but also because PTL and PTB impart a substantial financial burden on the health care industry, costing more than 40 billion annually (adjusted) in the United States alone (Behrman and Butler, 2007). It is clear that new strategies must be employed to mitigate this obstetric dilemma.

This work was supported by National Institutes of Health Eunice Kennedy Shriver National Institute of Child Health and Human Development [Grant R01-HD091114] (to I.L.O.B.)

https://doi.org/10.1124/jpet.120.000427.

S This article has supplemental material available at jpet.aspetjournals.org.
In contrast to most smooth muscle types, cyclic nucleotides (cGMP/cAMP) are not the dominant mediators of myometrial quiescence (Bradley et al., 1998; Lai et al., 2016; Barnett et al., 2018). Interestingly, nondiseased myometrium will readily relax to nitric oxide (NO), whose canonical action in most smooth muscle types lies in cGMP/Protein Kinase G activation, but whose primary actions differ in the myometrium through protein $S$-nitrosation. It is well established that NOmediated protein $S$-nitrosation (SNO) imparts a wide range of effects on the cell and that the disparate regulation of SNOs correlates with dozens of diseases (Foster et al., 2003; Barnett and Buxton, 2017). Protein $S$-nitrosations are not only dysregulated in the myometrium of patients with spontaneous preterm labor (Ulrich et al., 2012), but the functional effect of these SNOs on contractile-associated proteins (CAPs) underlies uterine quiescence (Barnett et al., 2018).

Connexin-43 (Cx43) is a member of large family of connexins and pannexins that actively mediate cell-cell communication (Söhl and Willecke, 2004), including the myometrium (Pierce

ABBREVIATIONS: $\beta 3-\mathrm{AR}, \beta 3$ adrenergic receptor; AUC, area under the curve; CAP, contractile-associated protein; Cx43, connexin-43; Cx43-pS368 - Cx43 O-phosphorylated at serine 368 DAPI, 4',6-diamidino-2-phenylindole; eNOS, endothelial NO synthase; EtBr, ethidium bromide; 18 $\beta$-GA, 18 $\beta$-glycyrrhetinic acid; GJC, gap junction channel; GSNO, S-nitrosoglutathione; GSNOR, GSNO reductase; HC, hemichannel; HC ( L-NNA N ${ }^{5}$-[imino(nitroamino)methyl]-L-ornithine LN 2 , liquid nitrogen; NO, nitric oxide; NP, nonpregnant; OT, oxytocin; phUSMC, pregnant human uterine smooth muscle; PTB, preterm birth; PTL, preterm labor; PTNL, preterm nonlabor; SNO, S-nitrosothiol; sPTL, spontaneous PTL; TAT, transactivator of transcription; TL, term labor; TNL, term nonlabor. 
et al., 2002). $\mathrm{Cx} 43$ functions as either a hemichannel (HC) where it promotes quiescence through the permeation of prostaglandin $\mathrm{E}_{2}$ (Burra and Jiang, 2009) and other lowmolecular-weight molecules (Hansen et al., 2014) from the cell, or as two such HCs in opposing membranes combining to form a gap junction channel (GJC) where it couples cells electrically to facilitate the propagation of contractile signals. The GJC/HC transition is largely driven by C-terminal phosphorylations (Leithe et al., 2018), and in some cell types, $\mathrm{HC}$ and GJC permeation is altered by its SNO state, particularly by nitrosation of C271 (Straub et al., 2011). Given that conditions promoting the $\mathrm{Cx} 43 \mathrm{HC}$ state and GJC inhibition may serve to facilitate myometrial quiescence, here we have elected to explore the functional consequences of $S$-nitroso regulation of $\mathrm{Cx} 43$ in human myometrium.

The conspicuous dearth of tocolytic strategies is due in part to our collective failure to better understand the mechanisms that underlie the biochemical regulation of uterine smooth muscle relaxation. Both the cGMP independence of myometrial relaxation to NO (Bradley et al., 1998) and the dysfunction of preterm laboring myometrium to NO-mediated relaxation (Barnett et al., 2018) are known. What drives spontaneous preterm labor (sPTL) is not. The importance of NO-mediated protein $S$-nitrosation in the myometrium during pregnancy, coupled with the critical nature of $\mathrm{Cx} 43$ as a myometrial CAP, makes $\mathrm{Cx} 43$ an attractive target of study. Here we investigate the regulation of $\mathrm{Cx} 43$ during pregnancy/parturition and the effect of $\mathrm{NO}$ on $\mathrm{Cx} 43$ function as well as the tocolytic potential for therapeutics that mediate SNOs and $\mathrm{Cx} 43$ activity.

\section{Materials and Methods}

Tissue Collection. Human tissue collection has been carried out in accordance with the Declaration of Helsinki and approved by the Institutional Review Board at the University of Nevada Biomedical Review Committee for the protection of human subjects. Human uterine biopsies were obtained with written informed consent from mothers with singleton pregnancies undergoing Cesarean section without known infection or rupture of membranes (premature rupture of the membrane/preterm premature rupture of the membrane), as previously described (Barnett et al., 2018). All experiments were performed in accordance with National Institutes of Health guidance on the use of human tissues in research. Exclusion criteria include age $<18$ years; any history of drug abuse; comorbid diagnoses, such as human immunodeficiency virus infection or AIDS; hepatitis C infection; uncontrolled diabetes; renal disease; preeclampsia; intrauterine growth restriction; placenta previa; and any use of steroids other than betamethasone, including topical use during pregnancy. Patients who were positive for severe acute respiratory syndrome coronavirus 2 were also excluded from this study. Tissues were transported to the laboratory immediately in cold Krebs' buffer (adjusted to $\mathrm{pH} 7.4$ ) containing (in $\mathrm{mM}$ ): $\mathrm{NaCl}$ (118), $\mathrm{KCl}$ (4.75), $\mathrm{CaCl} 2$ (2.5), $\mathrm{KH} 2 \mathrm{PO} 4$ (1.2), $\mathrm{NaHCO}_{3}(25), \mathrm{MgCl} 2$ (1.2), and dextrose (20). Tissues were dissected under magnification to isolate smooth muscle, employed in contractile experiments or snap-frozen in liquid nitrogen $\left(\mathrm{LN}_{2}\right)$, and stored at $-150^{\circ} \mathrm{C}$. Patients who were pregnant and laboring ranged from 39 to 41 weeks gestation, with the mean at 39 weeks. Patients who were preterm and laboring without evidence of infection, premature rupture of the membrane, or preeclampsia ranged from 29.2 to 36 weeks of gestation, with the mean being 33.6 weeks.

Animal studies were approved by the University Institutional Animal Care and Use Committee. All experiments were conducted in accordance with National Institutes of Health guidelines for the use of vertebrate animals in research. Inbred Dunkin-Hartley Guinea pigs (Elm Hill, Chelmsford, MA) were purchased as either virgin juveniles
(300-350 g) and bred on site or as timed pregnancies (30-35 days). Nonpregnant guinea pigs were estrogen-primed ( $3 \mathrm{mg} / \mathrm{kg} \beta$-estradiol) 48 hours prior to tissue collection to ensure alignment of estrous cycles. Virgin female guinea pigs and timed pregnant animals were sacrificed under isoflurane anesthesia.

Western Blot. Protein was isolated in mitogen-activated protein kinase buffer containing (in mM): Tris-HCL pH 6.8 (60), glycerol (1\%), SDS (2\%), leupeptin (0.001), EGTA (1), EDTA (1), 4-(2-aminoethyl) benzenesulfonyl fluoride hydrochloride (1), $\mathrm{Na}_{3} \mathrm{VO}_{4}$ (1), and protease/ phosphatase inhibitors (PPC110; Sigma Aldrich, St. Louis, MO). Samples were crushed using $\mathrm{LN}_{2}$ with mortar and pestle, and this was followed by 5 minutes in a tissue homogenizer. Sample concentrations were determined using EZQ (R33200; Thermo Fischer, Waltham, MA). Note that " $n$ "s were not equal for all conditions because of a scarcity of samples, particularly sPTL.

For $\mathrm{Cx} 43$ total protein, $40 \mu \mathrm{g}$ of protein lysate was run at $200 \mathrm{~V}$ for 45 minutes on a 4\%-20\% PAGE gel and transferred to nitrocellulose blocked in Licor blocking buffer. The Western blot was labeled with mouse anti-Cx43 polyclonal $1^{\circ}$ (1:1000, CX-1B1; Thermo Fischer), and this was followed by either Alexa Fluor 680-donkey anti-mouse $2^{\circ}$ (1:25k ab175774; Abcam, Cambridge, MA) or IRDye 800-donkey antimouse $2^{\circ}$ (1:25k, ab216774; Abcam). Cx43 expression was normalized to rabbit anti-GAPDH (1:1000, 2118S; Cell Signaling Technology, Danvers, MA) followed by either Alexa Fluor 680-goat anti-rabbit $2^{\circ}$ (1:25k, ab216773; Abcam) or IRDye 800-donkey anti-Rabbit (1:25k, 926-32213; Licor Biotechnology, Lincoln, NE). For pS368:S368 blots we used rabbit anti-pS368-Cx43 $1^{\circ}(1: 1000$, ab30559; Abcam) and IRDye 800-goat anti-rabbit $2^{\circ}(1: 25 \mathrm{k}$, ab216773) followed by mouse anti-Cx43 polyclonal $1^{\circ}$ (1:1000, CX-1B1: Thermo Fischer) and Alexa Fluor 680-donkey anti-mouse $2^{\circ}$ (1:25k, ab175774). $S$-nitrosated proteins gels were run as described above with $30 \mu$ l of eluted totalSNO proteins (see Biotin Switch and Streptavidin Pulldown method) with a reversible 680-nm total proteins stain, Licor Revert (part number 926-11010; Licor), or with the $\mathrm{Cx} 43$ antibody described above.

Contractile Studies. Strips of myometrium $(? 0.5 \times 15 \mathrm{~mm})$ were clip-mounted to a force transducer and isometrically stretched to an initial tension of $1.2 \times$ tissue length in an organ bath (DMT 820MS, Danish Myo Technology, Ann Arbor, MI) containing Krebs-Henseleit buffer (Barnett et al., 2018). Tissues were maintained at $37^{\circ} \mathrm{C}$ and gently bubbled with balanced oxygen $\left(95 \% \mathrm{O}_{2}, 5 \% \mathrm{CO}_{2}\right)$. Tissues were then challenged with $\mathrm{KCl}(60 \mathrm{mM}$ replacing $\mathrm{NaCl})$ for 3 minutes, which was followed by washout, and then they were allowed to equilibrate for 1 hour, during which time regular spontaneous contractions were seen. Only tissues that responded to $\mathrm{KCl}$ challenge were employed in experiments. Under some conditions, tissues were further challenged with oxytocin (OT) ( $8 \mathrm{nM}$ ), which was followed by washout. Tissues served as their own controls based on tension prior to addition of drug. Data were analyzed with LabChart (version 8.1.12, Win10; ADInstruments., Colorado Springs, CO).

Biotin Switch and Streptavidin Pulldown. Myometrial tissue samples ( $n=4$ patients) were hung in a tissue bath (see Contractile Studies) and exposed to either oxytocin ( $8 \mathrm{nM}$, three strips per patient) or oxytocin followed appoximately 10 minutes later by $S$-nitrosoglutathione (GSNO) $(300 \mu \mathrm{M}$, three strips per patient) at the start of a contraction and then snap-frozen with $\mathrm{LN}_{2}$ at either peak contraction or maximal relaxation and stored in amber tubes (to protect $S$-nitrosation) at $-150^{\circ} \mathrm{C}$. Proteins were initially isolated in mitogen-activated protein kinase buffer with $2 \%$ sodium dodecyl sulfate (SDS) (see Western Blot). For the biotin switch (Jaffrey and Snyder, 2001), $1397 \mu \mathrm{g}$ of total protein per sample was then suspended in HEN buffer containing (in millimolar): HEPES (25), EDTA (1), and neocuproine (0.1), pH 7.7. An additional 2.5\% SDS (final) and $30 \mathrm{mM} \mathrm{N}$-ethylmaleimide were added to block free thiols. Samples were incubated at $50^{\circ} \mathrm{C}$ in the dark for 20 minutes with frequent vortexing. Three volumes of $-30^{\circ} \mathrm{C} 100 \%$ acetone were added to each sample, and proteins were precipitated at $-30^{\circ} \mathrm{C}$ overnight and collected by centrifugation at $3000 \times \mathrm{g}$ for 10 minutes. After rinsing with $70 \%$ acetone, protein pellets were dried using dry nitrogen and then resuspended in HENS (HEN $+1 \%$ SDS) with $10 \mathrm{mM}$ ascorbate (to reduced SNO proteins) and 
0.25 mg/ml biotin-HPDP (16459; Cayman Chemical, Ann Arbor, MI) and rotated at room temperature for 1 hour. Proteins were precipitated and rinsed as before and resuspended in a mixture of HENS $(25 \%, 87 \mu \mathrm{l})$ and neutralization buffer $(50 \%, 174 \mu \mathrm{l})$ containing (in $\mathrm{mM}$ ): HEPES (25), $\mathrm{NaCl}$ (100), EDTA (1), 0.5\% SDS (pH 7.5), and $75 \mu$ l of magnetic streptavidin beads (spherotech svmx-10-10; spherotech, Lake Forest, IL). Samples were washed five times with ten volumes of neutralization buffer in a magnetic stand and then recovered in $35 \mu$ l elution buffer containing a 1:10 dilution of $\mathrm{HENS} / \mathrm{H}_{2} \mathrm{O}$ with $1 \% \mathrm{v} / \mathrm{v} \beta$-mercaptoethanol. Two proteins pellets from GSNO-treated samples were lost during a rinse phase and excluded from the data set.

Cell Culture. Human embryonic kidney (HEK) 293 (p10-p25; American Type Culture Collection, Manassas, VA) and telemorized (human telomerase reverse transcriptase - hTRT) pregnant human uterine smooth muscle (phUSMC) cells [p20-p30; created in-house (Heyman et al., 2013)] were grown in Dulbecco's modified Eagle's medium with $50 \mathrm{U} / \mathrm{ml}$ streptomycin, $50 \mu \mathrm{g} / \mathrm{ml}$ penicillin, and $10 \% \mathrm{FBS}$. phUSMC cells were further supplemented with estrogen $(15 \mathrm{ng} / \mathrm{ml})$ and progesterone $(200 \mathrm{ng} / \mathrm{ml})$. All cells were cultured in a balanced oxygen $\left(95 \% \mathrm{O}_{2}, 5 \% \mathrm{CO}_{2}\right) 37^{\circ} \mathrm{C}$ incubator.

Ethidium Bromide Assay. HEK293 and phUSMC cells were seeded (approximately 2500 cells/well) in 96-well plates (94.6000.024, Lumox Multiwell; Sarstedt, Newtown, NC) and grown to $50 \%-$ $80 \%$ confluency. Experimental protocol was modified from (Contreras et al., 2003). Twenty-four to 48 hours after seeding, the medium was exchanged for HEPES-buffered Krebs-Ringer (-) $\mathrm{Ca}^{2+}$ solution containing (in mM): $\mathrm{NaCl}(120), \mathrm{KCl}(5), \mathrm{MgCl}_{2}$ (1), $\mathrm{NaHCO}_{3}$ (25), HEPES (5.5), and D-glucose (1.1), $\mathrm{pH} 7.4, \pm \mathrm{CaCl}_{2}$ (2.5, as dictated by experiment). Ten micromolar ethidium bromide ( $\mathrm{EtBr}$ ) was added to each well \pm GSNO $(300 \mu \mathrm{M})$ or transactivator of transcription (TAT)Gap19 (100 $\mu \mathrm{M}$, a membrane-permeable $\mathrm{Cx} 43 \mathrm{HC}$ inhibitor) and then returned to the cell culture incubator for 5 minutes. After this, all wells were rinsed three times with $37^{\circ} \mathrm{C}$ HEPES-buffered Krebs-Ringer (-) $\mathrm{Ca}^{2+}$. This was denoted at $\mathrm{t}=0$, and the plates were returned to the incubator. At each experimental time point (0, 30, 60, or 90 minutes), treated cells were exposed to paraformaldehyde to halt progression of $\mathrm{EtBr}$ intercalation and then rinsed three times with buffer. Each well was then treated with DAPI (for cell counts), which was followed by three rinses. Plates were imaged on an ImageExpress Nano (Molecular Devices, San Jose, Ca) at $4 \times$ using MetaExpress software (v.6.5.4.532) at a fixed exposure time of 1500 milliseconds. Data collection and analysis were limited to a square in the middle of each well covering $32.63 \%$ with an average of 1024 cells to avoid incorporation of anomalous growth patterns common near the periphery of plates. Plate images in Fig. 3 are magnified $6.8 \times(300 \times 300 \mathrm{px})$ and false-colored (blue, DAPI: green, EtBr) to better visualize EtBr uptake but were analyzed using the full scan with ImageJ (v. 2.0.0-rc-69/ $1.52 \mathrm{p}$ ). Cell counts were determined by setting an appropriate threshold, which was followed by "Analyze Particles" ( Infinity) on the DAPI channel. EtBr uptake was determined by "area fraction" of the EtBr channel using fixed threshold to avoid altering the analyzed signal from well to well. Area fractions were normalized to cell count, and then each normalized area fraction was further normalized to the area fraction of the negative control $[(-) \mathrm{EtBr}]$ at each time point to account for noise in the background signal. $t=0$ was set to "zero," and data are displayed as a fold increase in fluorescent signal from $t=0$.

Statistical Analysis. For organ bath experiments (Figs. 2, 4, and 6) in which multiple tissue strips per patient were tested, each subsampling was pooled into a single " $n$," and each data set consisted of three to five patients (" $n$ "s, see Results for specific values) except for when control tissue was nonviable for the full experimental duration, in which case the data were collected from a new sample. Each " $n$ " is signified as a tick on the graph's $x$-axis, and the overlaid bar graph signifies the nested mean with $95 \%$ confidence interval error bars. Area under the curve (AUC) was defined as the period from the beginning to end of each contractile period. The last three contractions of each dosing and control period were analyzed. Peak tension was defined as the maximum tension at the height of contraction and subtracted from the minimum tension for each given contraction. Each tissue strip was normalized to its own baseline prior to dosing and then to the average of all control strips (controls are volume equivalents of drug solvent; $\mathrm{EtOH}$ for $18 \beta$-glycyrrhetinic acid (18 $\beta$ GA), DMSO for nebivolol, and Krebs-Henseleit buffer for TAT-Gap19, $\mathrm{N}^{5}$-[imino(nitroamino)methyl]-L-ornithine [L-NNA], and GSNO). The average of all controls for each " $n$ " was set to a nominal value of " 1 " so that data were presented as a "fold change from control." For Western blot analysis, each sample (guinea pig and human) was from a patient who was unique, treated at an individual " $n$," and represented by individual dots in Fig. 1.

For all experiments, $t$ tests were unpaired and two-tailed. Normally distributed data were analyzed with a Welch's correction to account for variable S.D., whereas non-normal data were subjected to a Mann-Whitney test. Likewise, either an ordinary one-way ANOVA test was employed or a Kruskal-Wallis test was used for nonparametric data as appropriate. All error bars on graphs displayed as 95\% confidence interval. Samples were randomized but not blinded, as inclusion/exclusion criteria and analysis parameters were established prior to experimentation and not subject to change. All data were analyzed using Prism (v. 8.4.3; Graphpad Software, San Diego, CA).

\section{Results}

Cx43 Protein Expression in sPTL. A multitude of genes and proteins are differentially regulated in women who experience preterm labor (Paquette et al., 2018; Knijnenburg et al., 2019 ). We previously determined that $S$-nitrosoglutathione reductase (GSNOR), a negative modulator of NO availability, is upregulated in SPTL myometrium, which decreases the availability of NO and reduces total protein $S$-nitrosations (Barnett et al., 2018). Here we sought to determine whether $\mathrm{Cx} 43$ is also dysregulated in sPTL myometrium. First, to establish a baseline of $\mathrm{Cx} 43$ expression throughout the entire gestational period (early, mid, late), something that cannot practically be done in women, we employed an animal model of preterm labor: the guinea pig. Data gathered from early gestation in the guinea pig allow us to better compare human preterm protein expression with a known standard. The guinea pig is preferred over other animal models, such as the mouse (Yellon et al., 2009), because like humans guinea pigs do not experience progesterone withdrawal prior to the onset of labor (Nnamani et al., 2013).

In the guinea pig, when compared with nonpregnant (NP) myometrium ( $n=6$ ), Cx43 expression was found to increase in early pregnancy (days 15-30: $P=0.0025, n=7$; Fig. 1A; Supplemental Fig. 1A) and remain elevated throughout (mid, days 31-59: $P=0.0449, n=6$; late, days $60+: P=0.0373, n=6$ ). Interestingly, expression did not vary among early, mid, and late pregnancy (ANOVA, $P=0.9611$ ). Based on the data provided by our animal model, we then analyzed human myometrial expression of Cx43 (Fig. 1B; Supplemental Fig. 1B). In human tissue, we found a similar trend in which relative to NP myometrium $(n=14), \mathrm{Cx} 43$ expression was significantly higher in all pregnancy groups (PTNL: $P=0.0033$, $n=6,32.0$ weeks \pm 2.32 ; term labor (TL: $P<0.0001, n=14$, 39.0 weeks \pm 0.44 ; TNL: $P<0.0001, n=14,38.8$ weeks \pm 0.67 ), with the notable exception of sPTL (sPTL: $P=0.8411, n=6$, 33.64 weeks \pm 3.25 ). As with the guinea pig, there was also no appreciable difference in expression of $\mathrm{Cx} 43$ in uncomplicated states of pregnancy (PTNL:TL:TNL, $P=0.5190$ ). 


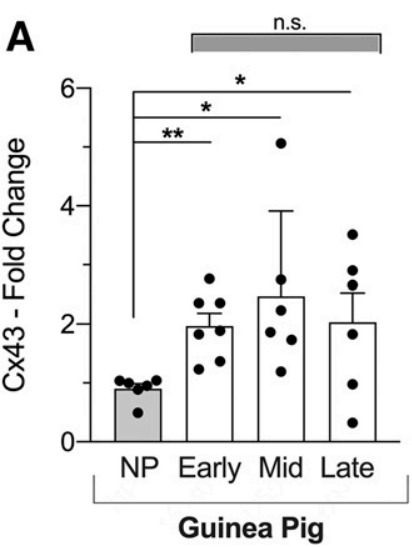

Effect of NO on Cx43 Phosphorylation and $\boldsymbol{S}$-Nitrosation. The expression of $\mathrm{Cx} 43$ in the myometrium is only one of several important metrics when establishing its role in contractile dynamics. It is well known that Cx43's phosphorylation state, particularly at S368 on the C terminus, is critical to GJC (contraction) function (Lampe et al., 2000; Solan and Lampe, 2014). Because myometrium is known to relax to NO independent of the canonical cGMPProtein Kinase G pathway (Buxton, 2004), we sought to determine whether NO would facilitate an increase in $\mathrm{Cx} 43 \mathrm{O}$-phosphorylation at S368 (pS368). Using an ex vivo organ bath, we attached human myometrial tissue strips to a force transducer in a physiologic buffer and then exposed the tissue to either oxytocin ( $8 \mathrm{nM})$, after which it was snap-frozen with $\mathrm{LN}_{2}$ (spray gun) at peak contraction, or to oxytocin, which was followed by NO (GSNO, $300 \mu \mathrm{M}$ ) and then snap-frozen at maximal relaxation (TNL: $n=4$, three samples per " $n$ "). Total protein lysate was extracted from the samples, and the ratio of pS368:S368 was analyzed via Western blot (Fig. 2A; Supplemental Fig. 2A). We found that the ratio of pS368:S368 was approximately 2.4-fold higher $(P=0.0281)$ in myometrium treated with $\mathrm{NO}$ as compared with tissue treated with OT, intimating a role of $\mathrm{NO}$ in $\mathrm{Cx} 43$-mediated quiescence.

In addition to phosphorylation, we examined $\mathrm{Cx} 43$ $S$-nitrosation, a posttranslational modification that acts as a critical mediator of protein function in the myometrium. Total protein $S$-nitrosation in the myometrium can vary wildly based on the pregnancy state, particularly in women who experience sPTL (Ulrich et al., 2012). Moreover, this posttranslational modification is known to affect contractile dynamics (Barnett et al., 2018). S-nitrosation of $\mathrm{Cx} 43$ has been shown in other tissue types to alter the protein's function (Retamal et al., 2006; Lillo et al., 2019); therefore, we sought to determine whether NO-mediated phosphorylation of $\mathrm{Cx} 43$ at S368 correlates with $\mathrm{Cx}-43 \mathrm{~S}$-nitrosation. Using the same protein lysates as above, we performed a biotin switch assay to identify whether $\mathrm{Cx} 43$ was $S$-nitrosated when exposed to $\mathrm{NO}(300 \mu \mathrm{M})$. We found that SNO-Cx43 levels increased 2.08 -fold in NO-treated samples $(P=0.0046)$ over OT-treated samples (Fig. 2B; Supplemental Fig. 2B), whereas total protein SNOs increased 1.37-fold $(P=0.0274$, Fig. 2C; Supplemental Fig. 2C).

Effect of NO on Cx43 HC Function. After determining that NO correlates with both an increase in the pS368:S368 ratio and $\mathrm{Cx} 43 \mathrm{~S}$-nitrosation, we next sought to determine whether NO would directly affect its function. This was accomplished through an EtBr assay (Contreras et al., 2003), which is measured as an increase in fluorescent signal as $\mathrm{EtBr}$ intercalates with nucleotides after passing through $\mathrm{Cx} 43 \mathrm{HCs}$ in the membrane. Telemorized phUSMC cells and HEK293 cells, which show no appreciable Cx43 expression (Fig. 3D), were grown to approximately $50 \%-80 \%$ confluence $(n=3$, approximately 3500 cells per well) and exposed to $10 \mu \mathrm{M}$ EtBr for 5 minutes in KrebsRinger buffer (-) $\mathrm{Ca}^{2+}$. After exposure, the experimental buffer was exchanged for fresh Krebs-Ringer buffer $(-) \mathrm{Ca}^{2+}(t=0)$ and placed in a $37^{\circ} \mathrm{C}$ incubator $\left(95 \%: 5 \%, \mathrm{O}_{2}: \mathrm{CO}_{2}\right)$. At each time point ( $t=0,30,60,90$ minutes), treated cells were washed and fixed with paraformaldehyde to halt the reaction. Cells were then imaged at $4 \times$, and the relative fluorescent increase (normalized to total cell count by DAPI labeling) over $t=0$ was observed. A higher fluorescent signal implies a prolonged open probability of the channel during the EtBr loading phase. Under baseline conditions, relative fluorescent signal increased by 4.58 -fold $( \pm 0.734)$ at $t=90(P=0.0089$, Fig. 3, A and $\mathrm{C})$, which was completely eliminated by the use of $100 \mu \mathrm{M}$ TAT-Gap19 $(P=0.700)$, a membrane-permeable inhibitor selective to the HC (Abudara et al., 2014). The addition of NO (GSNO, $300 \mu \mathrm{M})$ increased the fluorescent signal by 3.36-fold $( \pm 0.698)$ over $\mathrm{t}=0(P=0.0365)$; however, at 90 minutes GSNO treatment did not increase the fluorescent signal above baseline conditions at 90 minutes $(P=0.2963)$. To determine whether this occurred because the assay was run in $\mathrm{Ca}^{2+}$-free buffer, which facilitates an HC open-channel state (Li et al., 1996), we evaluated the effect of physiologic extracellular $\mathrm{Ca}^{2+}$ (2.5 mM), which closes the HC (Ek-Vitorín et al., 2018). We found that the addition of NO (GSNO, $300 \mu \mathrm{M}$ ) significantly increased EtBr uptake over untreated baseline at 90 minutes $(P=0.0119$, Fig. 3B). The fluorescent signal in HEK293 cells, which do not appreciably express $\mathrm{Cx} 43$ protein, was unchanged throughout the 90-minute observation period in both the untreated (ANOVA, $P=0.8621$ ) and NO-treated (ANOVA, $P=0.2533$ ) HEK293 cells (Fig. 3A).

Cx43 HC Inhibition and Tocolysis. It is well established that $\mathrm{Cx} 43$ is a critical facilitator of coordinated muscle contraction, so here we consider whether $\mathrm{Cx} 43$ inhibition exhibits useful tocolytic properties. Two $\mathrm{Cx} 43$ inhibitors were selected for their actions on the GJC and HC: 1) $18 \beta$-GA, a compound found in the roots of Glycyrrhiza glabra L. (black licorice) that inhibits GJC and HC, and 2) TAT-Gap19, an HCselective inhibitor consisting of a nine-amino-acid peptide fragment from the $\mathrm{Cx} 43$ cytosolic loop, which contains a TAT modification (transactivating transcriptional activator from 


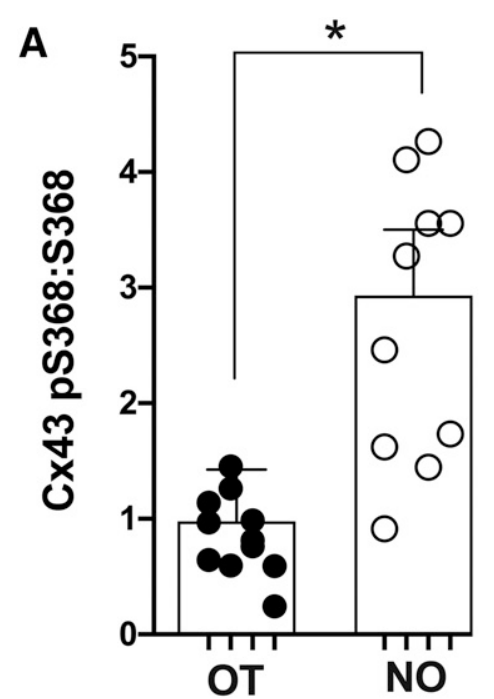

B
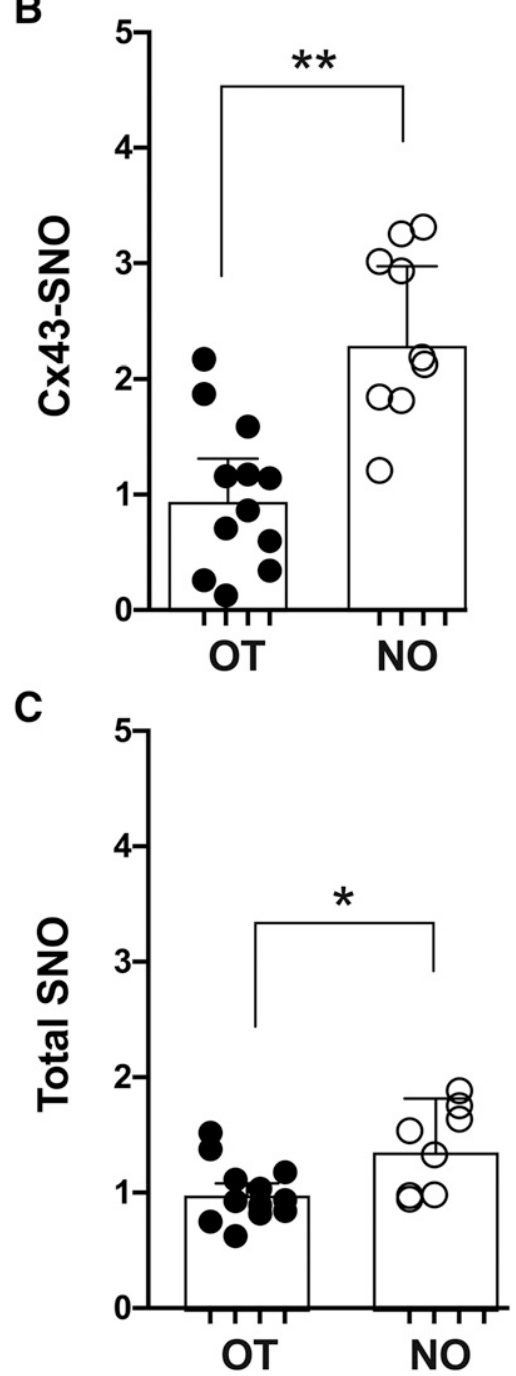

Fig. 2. Cx43 $S$-nitrosation promotes GJC inhibition (Cx43-pS368) in human myometrium. Human myometrial tissue (TNL) was hung in an organ bath and exposed to either OT or NO. (A) The ratio of pS368, a posttranslational modification that promotes GJC inhibition (quiescence), was approximately 2.4 -fold higher in NO-treated tissue $(P=$ 0.0281 ), (B) which also correlated to approximately2-fold increase in Cx43 $S$-nitrosation $(P=0.0046)$. (C) Total protein $S$-nitrosation in the tissue lysate also increased by approximately1.4-fold over OT-treated tissue $(P=0.0274)$. human immunodeficiency virus 1; Fig. 4) that greatly increases cell permeability and action on the channel (Abudara et al., 2014). Based on our previous data, we posited that $18 \beta$-GA would blunt contractions by preventing the propagation of the contractile signal between uterine smooth muscle cells, whereas TAT-Gap19 would most likely confer positive inotropic effects by inhibiting normal $\mathrm{HC}$ function.

TAT-Gap19 was tested as a single dose at $100 \mu \mathrm{M}$ (or buffer vol. equivalent) for 60 minutes in $\mathrm{KCl}$-stimulated $(60 \mathrm{mM}$, 3 minutes) tissue without the addition of OT ( $n=3$, two strips per patient). We hypothesized that TAT-Gap19 would promote a contractile state through HC-specific inhibition. Contractions from TNL myometrium that is not treated with OT will run down (unpublished data); therefore, we were interested in determining whether $\mathrm{HC}$ inhibition would promote contractions in tissue that would otherwise become quiescent. All TAT-Gap19-treated tissue maintained regular contractions throughout the dosing period (Fig. 4A), whereas all but one control tissue ran down completely (contractions returned in all control samples after $\mathrm{KCl}$ stimulation after 60-minute dosing period). Both AUC $(P<0.0001)$ and peak tension $(P=0.005)$ were significantly higher in TAT-Gap19-treated tissue (Fig. 4B).

Coadministration of a Cx43 GJC Inhibitor and Endothelial NO Synthase Activator. A primary concern when administering any tocolytic is the potential for off-target effects on the fetus and mother. Fetal toxicity not only limits which drugs may be used but also at which concentrations. Because of this, we propose that the coadministration of two or more drugs at modest doses may provide a complementary effect, particularly when each drug targets a known pathway associated with sPTL. We previously generated a limited data set in which nebivolol, an endothelial NO synthase (eNOS) activator, displayed tocolytic properties (Barnett and Buxton, 2018). Here we expanded upon that investigation and sought to establish whether the coadministration of nebivolol and $18 \beta$-GA, an Cx43 inhibitor, exerts enhanced negative inotropic effects.

To begin, we experimentally derived $\mathrm{IC}_{50}$ values for nebivolol (Fig. 5A) and 18 $\beta$-GA (Fig. 5B) using TNL myometrium ( $\log _{\text {drug }}$ vs. response) with the organ bath technique described above. We determined that the $\mathrm{IC}_{50}$ for nebivolol based on AUC was $8.26 \mu \mathrm{M}(n=3$ patients), whereas for $18 \beta$-GA it was $102 \mu \mathrm{M}(n=5$ patients $)$. Because nebivolol acts on endothelial $\beta 3$ adrenergic receptors ( $\beta 3-\mathrm{ARs})$ to produce NO through eNOS activation (Reidenbach et al., 2007) and potentially on $\beta 3$-ARs located on uterine myocytes, we also tested the effects of L-NNA (100 $\mu \mathrm{M}, 20$ minutes preincubation), a potent inhibitor of eNOS activity, on TNL tissue treated with $10 \mu \mathrm{M}$ nebivolol $(n=3$ patients per condition, one to three myometrial strips per patient) and found that nebivolol did not significantly decrease AUC in the presence of L-NNA $(P=0.1405$, unpublished data), suggesting that nebivolol's action on the myometrium rests primarily on NO production.

To test the effects of combination tocolytics, we first independently dosed TNL tissue $(n=3$ patients per condition, one to three myometrial strips per patient) at the approximate $\mathrm{IC}_{50}$ for nebivolol $(10 \mu \mathrm{M})$ and $18 \beta$-GA $(100 \mu \mathrm{M}$, Fig. $6 \mathrm{C})$. Roughly in line with our experimentally derived $\mathrm{IC}_{50}$ data, the AUC for nebivolol dropped to $49.9 \%( \pm 6.7)$ of control $(P<$ $0.0001)$, with $18 \beta$-GA at $33.8 \%( \pm 7.2)(P<0.0001)$, of which there was not a significant difference of AUCs between 

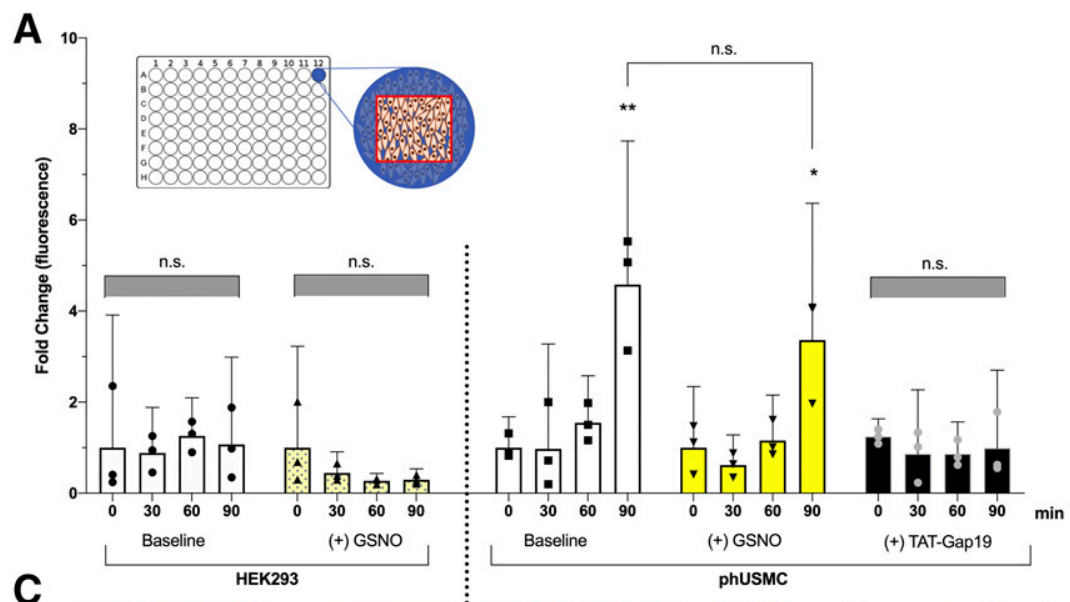

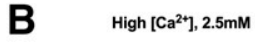
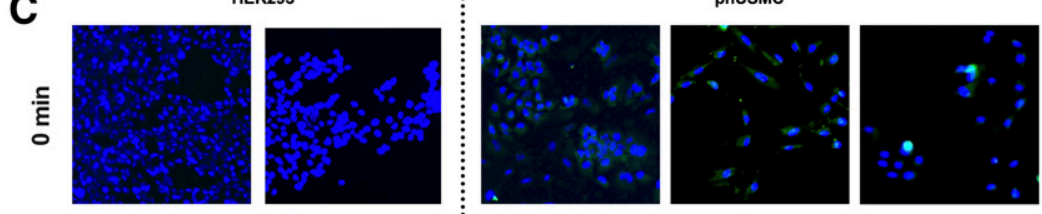

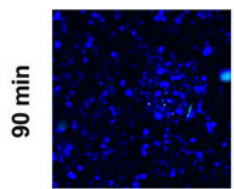

Baseline HEK293

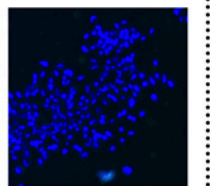

(+) GSNO

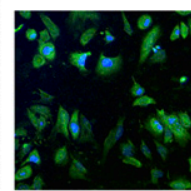

Baseline phUSMC

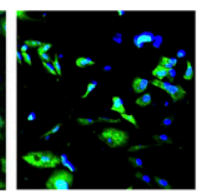

(+) GSNO phUSMC

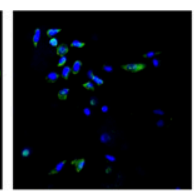

(+) TAT-GAP19 phUSMC
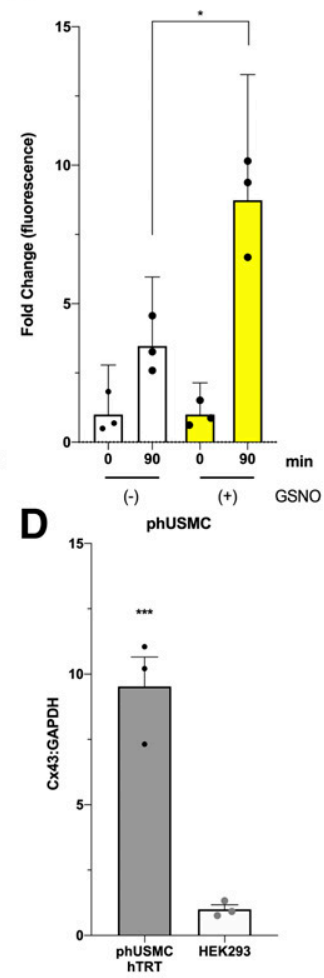

Fig. 3. Nitric oxide promotes $\mathrm{Cx} 43 \mathrm{HC}$ open state: $\mathrm{EtBr}$ selectively permeates $\mathrm{Cx} 43$ channels. (A and B) Human myometrial or HEK293 cells were exposed to $\mathrm{EtBr} \pm$ GSNO or TAT-Gap19 (HC blocker) in a $\mathrm{Ca}^{2+}$-free buffer for 5 minutes and then washed out. (A) Under baseline conditions $(P=0.0089$ ) and with GSNO $(P=0.0365)$, EtBr uptake through HCs was significantly higher by 90 minutes in myometrial cells but not in those exposed to TATGap19 $(P=0.700)$, whereas no appreciable uptake of EtBr was observed in HEK293 cells $(+)$ GSNO $(P=0.2533)$ or $(-)$ GSNO $(P=0.8621)$. (B) Under $2.5 \mathrm{mM} \mathrm{Ca}^{2+}$, which increases the closed-state probability of $\mathrm{Cx} 43$, fluorescent signal in myometrial cells exposed to GSNO increased significantly over baseline treatment at 90 minutes $(P=0.0119)$. (C) $300 \times 300$-pixel magnification of $4 \times$ acquired images represented in $(\mathrm{A})$ at $\mathrm{t}=0$ and $\mathrm{t}=90$, wherein cellular nuclei are false-colored blue (DAPI) and $\mathrm{EtBr}$ is green (Cx43). (D) Western blot data depicting the absence of $\mathrm{Cx} 43$ in HEK293 cells relative to telomorized (human telomerase reverse transcriptase - hTRT) uterine smooth muscle cells. n.s., not significant.

nebivolol and $18 \beta$-GA at their respective $\mathrm{IC}_{50}$ values $(P=0.1506$, Fig. 6A). Similarly, the peak tension after nebivolol $\mathrm{IC}_{50}$ administration decreased to $72.9 \%$ ( \pm 6.5 S.E.M.) of control $(P<0.0001)$, and for $18 \beta-\mathrm{GA}$ it decreased to $33.8 \%( \pm 7.2)$ $(P<0.0001$, Fig. 6B).

When nebivolol and $18 \beta$-GA were coadministered for 1 hour (10, $100 \mu \mathrm{M}$ respectively), their effects on AUC and peak force were additive. AUC dropped to $12.5 \%( \pm 2.5)$ of control $(P<0.0001)$, which was an additional $37.4 \%$ decrease over nebivolol alone $(P=0.0061)$ and an additional $21.3 \%$ decrease over $18 \beta$-GA ( $P=0.0088$, Fig. 6 A). Coadministration also decreased peak tension to $21.4 \%( \pm 4.8)$ over control $(P<0.0001)$, which constituted a $51.1 \%(P=0.009)$ and $19.3 \%(P=0.0396)$ drop in peak tension relative to their $\mathrm{IC}_{50}$ values with nebivolol and $18 \beta$-GA, respectively (Fig. 6B), and can be seen visually in the representative traces (Fig. 6C).
A

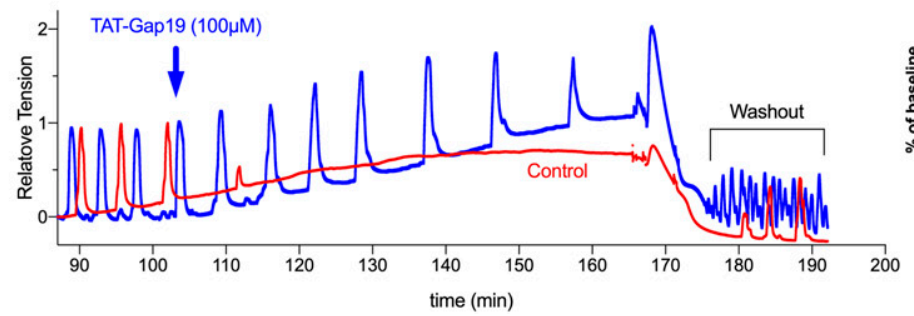

B

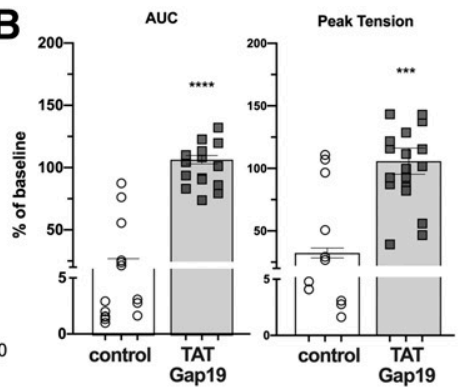

C

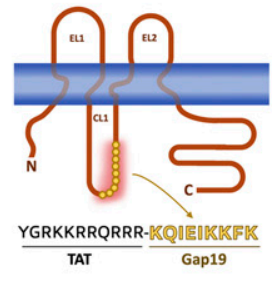

Fig. 4. Cx43 HC inhibition promotes myometrial contractions. Human myometrial tissue (TNL, $n=4)$ was $\mathrm{KCl}$-challenged (60 mM, $3 \mathrm{minutes}$ ) in an organ bath to initiate contractions but was not exposed to oxytocin. (A) Tissue treated with TAT-Gap19 (100 $\mu$ M), a Cx43 HC-selective inhibitor, maintained contractions throughout the experimental period, whereas control tissue lost all contraction by approximately 100 minutes (contraction returned upon second $\mathrm{KCl}$ challenge after washout). (B) In the control tissue AUC decreased by approximately $80 \%$ as compared with TATGap19-treated tissue $(P<0.0001)$ and peak tension falling approximately $69 \%(P=0.005)$. (C) TAT-Gap19 consists of a nine-amino-acid cytosolic loop fragment of $\mathrm{Cx} 43$ and a linked N-terminal TAT modifier, which increases membrane permeability and enhances its inhibitory effect. 
A

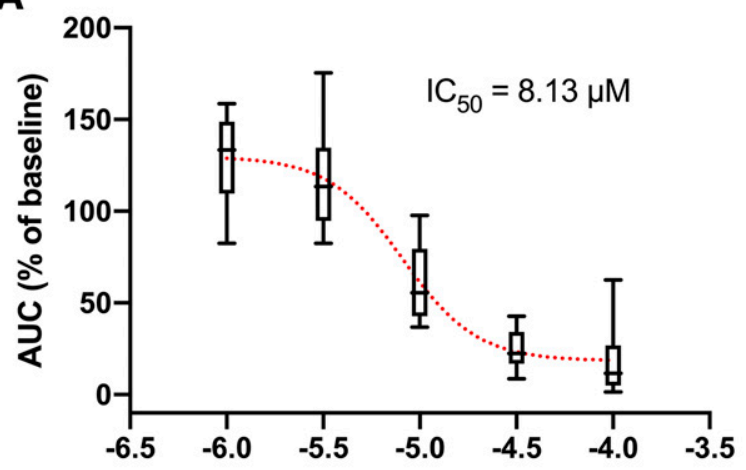

B

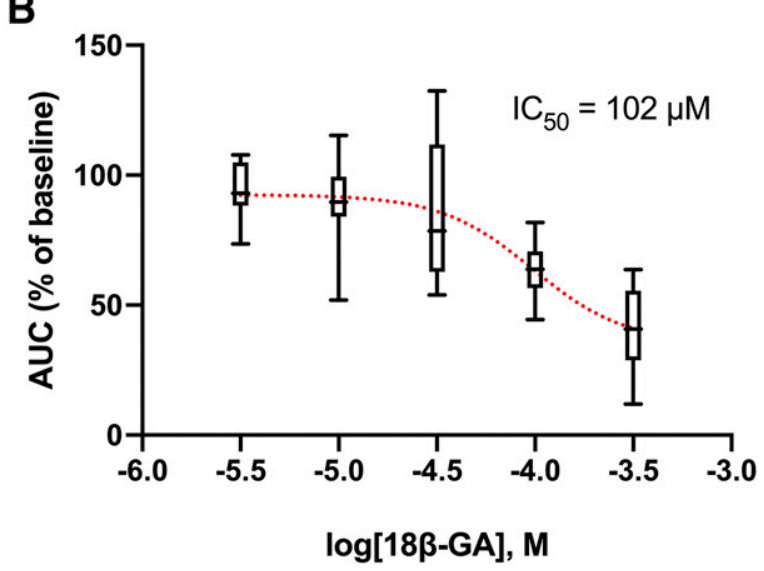

Fig. 5. Myometrial $\mathrm{IC}_{50}$ values of nebivolol and $18 \beta$-glycyrrhetinic acid. Nebivolol is known to increase the generation of nitric oxide through eNOS activation, whereas $18 \beta$-GA blocks Cx43 GJCs. TNL myometrium was hung in an organ bath and exposed to either (A) $1,3,10,30$, or $100 \mu \mathrm{M}$ nebivolol $(n=3)$ or (B) 3, 10,30, 100, or $300 \mu \mathrm{M} 18 \beta$-GA $(n=5)$ for 1 hour. Calculated $\mathrm{IC}_{50}$ values are based on the AUC of the last three contractions of the dosing period prior to washout and were 8.13 and $102 \mu \mathrm{M}$ for nebivolol and $18 \beta$-GA, respectively.

\section{Discussion}

Preterm birth remains the single greatest cause of neonatal morbidity and hospitalization after pregnancy (Miniño et al., 2006; Rundell and Panchal, 2017; Granese et al., 2019). The preterm birth rate in the United States and the United Kingdom has hovered between $8 \%$ and $12 \%$ for decades, resulting in 20,000 infant deaths annually in the United States alone (Martin et al., 2013). Novel tocolytic development will benefit from embracing the specific disparities found in women who experience sPTL in lieu of the "borrowed pharmacology" currently favored. For this reason, we sought to investigate the regulation and modulation of the important myometrial CAP protein, $\mathrm{Cx} 43$.

Connexins are ubiquitously expressed in most cell types (Söhl and Willecke, 2004). Cx43 is integral to muscle function, wherein its dysregulation can be consequential (Ai et al., 2000; $\mathrm{He}$ and Chen, 2016). Although data surrounding the expression of $\mathrm{Cx} 43$, per se, does not provide resolution concerning its conformation (GJC vs. HC vs. trafficking), it does afford information regarding the myocyte's state and tissue phenotype. Our animal model predicted that $\mathrm{Cx} 43$ expression should increase early in pregnancy and remain elevated throughout gestation (Fig. 1A). In human myometrium, our $\mathrm{Cx} 43$ expression data are consistent with our animal model (Fig. 1B) as well as with data from other laboratories (Pierce et al., 2002). Interestingly, we did not observe differential expression of $\mathrm{Cx} 43$ after onset of labor (TNL vs. TL) nor in preterm tissue as compared with term (PTNL vs. TNL). Importantly, $\mathrm{Cx} 43$ expression was significantly higher in all pregnancy states relative to NP, with the notable exception SPTL, in which $\mathrm{Cx} 43$ expression was on par with NP. Similar $\mathrm{Cx} 43$ dysregulation in other reproductive tissues during pregnancy affects birth timing; for instance, $\mathrm{Cx} 43$ has been found to be downregulated in first-trimester villi and decidua of women who experience recurrent pregnancy loss (He and Chen, 2016). Furthermore, Wnt-1 activation is known to increase expression of $\mathrm{Cx} 43$ in myocytes (Ai et al., 2000), and it has been shown that WNT1 is downregulated in the fetal membrane of women who experience PTL (Pereyra et al., 2018). As such, our data further correlate $\mathrm{Cx} 43$ dysregulation with aberrant labor, and because of Cx43's integral role as a smooth muscle $\mathrm{CAP}$ protein, this dysregulation suggests that $\mathrm{Cx} 43$ may be a unique target of interest for tocolytic development.

Beyond $\mathrm{Cx} 43$ protein expression, the posttranslational state of $\mathrm{Cx} 43$ is fundamental to its function. In particular, phosphorylation of S368 is of keen interest because this posttranslational modification decreases GJC conductance (Lampe et al., 2000) and facilitates its internalization (Boswellcasteel et al., 2016; Ribeiro-Rodrigues et al., 2017; Ek-Vitorín et al., 2018). Our finding that NO increases the ratio of pS368 in myometrium (Fig. 2A) is significant in that it bolsters a growing body of evidence that confirms our previous data demonstrating NO-mediated cGMP-independent relaxation of the human myometrium (Bradley et al., 1998). In addition to altering its phosphorylation state, we also determined that that $\mathrm{Cx} 43$ is directly $S$-nitrosated by NO during relaxation of the myometrium (Fig. 2B), which has been shown to alter conformation and conductance of the channel (Retamal et al., 2006; Straub et al., 2011; Dimitrova et al., 2017). Together, these data provide compelling evidence that NO's action on $\mathrm{Cx} 43$ serves as an important mediator of relaxation in the myometrium.

Based on our results, we elected to investigate the effect of $\mathrm{NO}$ on $\mathrm{HC}$ function. The $\mathrm{HC}$ is associated with quiescence in that it permeates prostaglandin $\mathrm{E}_{2}$ (Burra and Jiang, 2009) and other small molecular weight mediators, including ATP (King and Lampe, 2005), into the extracellular space. Cx43SNO-C271 has been shown to activate both the HC (Contreras et al., 2003) and the GJC (Straub et al., 2011) at the myoendothelial junction. In line with these findings, our data indicate that $\mathrm{NO}$ activates the $\mathrm{HC}$ in human uterine smooth muscle cells under physiologic extracellular $\mathrm{Ca}^{2+}$, and this activation is blocked with the addition of an HCselective inhibitor: TAT-Gap19 (Fig. 3). Our finding that the $\mathrm{HC}$ open state is correlated with the presence of NO provides additional data in support of the noncanonical relaxation of the myometrium by NO. Whether HC activation is critically mediated by SNO-Cx43 formation, pS368$\mathrm{Cx} 43$ formation, or both awaits future investigation.

The effect of NO on the biochemical state of $\mathrm{Cx} 43$ in the myometrium is compelling; however, simply modulating $\mathrm{Cx} 43$ 's SNO or $O$-phosphorylation state does not guarantee tocolysis in myometrial tissue. For this reason, we sought to determine whether pharmacological mediation of $\mathrm{Cx} 43$ and NO exhibits novel tocolytic properties. To this end, we first 


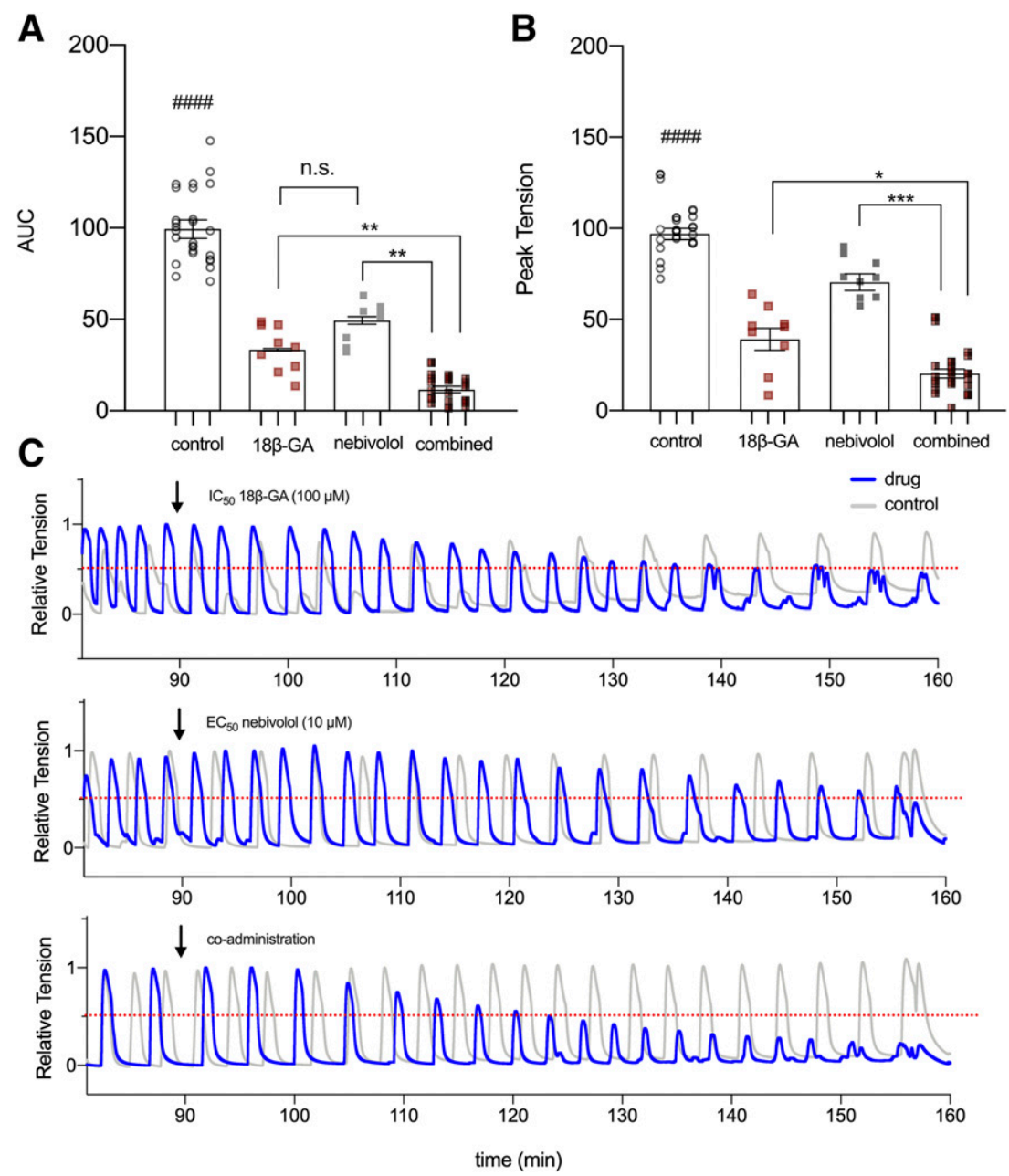

Fig. 6. Coadministration of nebivolol and $18 \beta$-glycyrrhetinic acid impart a synergistic negative inotropic effect. TNL myometrium ( $n=3$ per condition) was hung in an organ bath and exposed to either nebivolol $(10 \mu \mathrm{M}), 18 \beta$-GA $(100 \mu \mathrm{M})$, or a combination of both $(10,100 \mu \mathrm{M})$. (A) Relative to control there was a significant decrease in AUC for individual and combined doses (\#\#\#\#P $<0.0001, t$ test between control and each dosing scheme), and the coadministration of nebivolol and $18 \beta$-GA decreased the AUC to $12.5 \%( \pm 2.5)$ of control $(P<0.0001)$, which represents a $37.4 \%$ further decrease over nebivolol alone $(P=0.0061)$ and an additional $21.3 \%$ decrease over $18 \beta$-GA alone $(P=0.0088)$. (B) Similarly, relative to control there was a significant decrease in "peak force" for individual and combined doses (\#\#\#\#P<0.0001, $t$ test between control and each dosing scheme), and the coadministration of nebivolol and $18 \beta$-GA decreased peak tension to $21.4 \%( \pm 4.8)$ over control $(P<0.0001$ ), which constituted a $51.1 \%$ (nebivolol, $P=0.009)$ and $19.3 \%$ (18 $\beta$-GA, $P=0.0396)$ drop in peak tension relative to their $\mathrm{IC}_{50}$ doses. $(\mathrm{C})$ Relative change in tension after $\mathrm{IC}_{50}$ administration of "18 $\beta$-GA" (top panel), "nebivolol" (middle panel), or "both" (bottom panel) in TNL myometrium. Drug dosing represented in blue (-) and control tissue in gray (-). n.s., not significant.

independently overserved the effects HC and GJC inhibition on myometrial contractile dynamics. As we hypothesized, the inhibition of the HC with TAT-Gap19 conveyed positive inotropic effect on the myometrium (Fig. 4), further reinforcing the concept that the $\mathrm{HC}$ is critical to the maintenance of myometrial quiescence. Conversely, the inhibition of $\mathrm{Cx} 43$ with 18 $\beta$-GA, which also promotes Cx43-pS368 formation (Liang et al., 2008), blunted contractile dynamics (AUC) in a dose-dependent manner (Fig. 5B). Taken together, these data indicate that activation of the $\mathrm{HC}$ and inhibition of GJC may function in concert to mediate quiescence.

With the therapeutic potential of GJC inhibition established, we posited that increasing endogenous NO availability would further enhance tocolysis by promoting $\mathrm{Cx} 43 S$-nitrosation and serine $O$-phosphorylation (pS368) to increase HC activity and blunt that of the GJC. We have previously demonstrated in a limited manner that NO generation through eNOS activation (nebivolol, Bystolic, Allergan) (Barnett and Buxton, 2018) exhibits a tocolytic effect. Here we expanded upon that finding and determined that nebivolol conveys robust negative inotropic effects on the myometrium in a dose-dependent manner (Fig. 5A). Interestingly, because nebivolol is an agonist of $\beta 3$-ARs, we must consider that some of the effects of the drug may be the result of $\beta 3$-AR activation directly on uterine myocytes rather than solely on $\beta 3$-AR-mediated eNOS activation on the endothelium. In previously published work, we determined that the $\beta 3$-AR antagonist SR59230A reduced the action of nebivolol by approximately 50\% (Barnett and Buxton, 2018), and here we found that in the presence L-NNA, an eNOS antagonist, nebivolol, administered at its $\mathrm{IC}_{50}$ dose $(10 \mu \mathrm{M})$ does not significantly reduce AUC. Although the activation of $\beta 3$-ARs on uterine myocytes may in fact play a role in myometrial quiescence, here we show that nebivolol's actions on myometrial tissue are largely the result of NO generation. These data support the notion that GJC inhibition and protein $S$-nitrosation are fundamental drivers of myometrial quiescence.

A significant real-world problem when administering tocolytics is the effect on the fetus. The necessary high doses needed to blunt preterm labor with drugs like $\mathrm{MgSO}_{4}$, terbutaline, or nifedipine can affect fetal heart rate (Verdurmen et al., 2017), and a drug specifically designed as a tocolytic, atosiban, an oxytocin receptor antagonist, is not effective at delaying PTB at any dose (Flenady et al., 2014). Taken together, this presents an interesting pharmacologic conundrum. We believe that the solution may lie in the coadministration of multiple tocolytics at low doses. Not only might this put less stress on the fetus by limiting its exposure to the drugs, but we also suggest that by targeting multiple dysregulated pathways, the potential to halt PTL and delay PTB increases significantly. This concept is not entirely novel. Clinical trials with the coadministration of 
various $\beta$-adrenergic receptor modulators, such as ritodrine, in combination with other drugs [indomethacin (cyclooxygenase-1/ 2), $\mathrm{MgSO}_{4}$ (voltage-gated $\mathrm{Ca}^{2+}$ channel)] were carried out with no clear benefit (Vogel et al., 2014). These findings are not particularly surprising considering the limited role cyclic nucleotides play specifically in myometrial quiescence. Our approach differs in that we are targeting proteins and pathways known to be dysregulated in women who experience preterm labor. Not only is Cx43 dysregulated in sPTL myometrium (Fig. 1B), but we have previously shown that total protein $S$-nitrosations in the myometrium are decreased because of the overexpression of GSNOR, a catabolic degrader of NO, in sPTL myometrium (Barnett et al., 2018). It is for these reasons that we elected to coadminister $18 \beta-\mathrm{GA}$ and nebivolol at their $\mathrm{IC}_{50}$ values and found that the combined effect on AUC and peak tension was synergistic and all but abolished contractions (Figs. 5 and 6). Further studies must be conducted to determine whether the tocolytic properties of $18 \beta$-GA and nebivolol fully transfer to sPTL myometrium. This is a reasonable concern because the upregulation GSNOR in sPTL myometrium may subdue the tocolytic benefits of nebivolol-mediated NO generation, and the downregulation of $\mathrm{Cx} 43$ in sPTL may further reduce the negative inotropic actions of $18 \beta$-GA.

Although the solution to the problem that is sPTL continues to elude the scientific community, there is little doubt that to decipher this mystery we must better understand dysregulated pathways during affected pregnancies and in turn develop novel therapeutics that mitigate these disparities. $\mathrm{Cx} 43$ is a foundational CAP protein in the myometrium, and here we show that it is dysregulated in sPTL myometrium, and its function is moderated by NO. By inhibiting GJC activity and increasing endogenous NO availability, we were able to severely blunt contractions, reinforcing the concept that pharmacologic intervention of multiple dysregulated pathways during pregnancy enhances quiescence. Additional biochemical and genetic pathways associated with sPTL are being recognized with increased frequency and with this comes the potential for identifying new and effective tocolytics.

\section{Acknowledgments}

The authors would like to acknowledge Veronica Arinze for cell culture; Amy Savignac and Veronica Arinze for human tissue collection; and Coral Gramelspacher, Jennifer Burnham, and Irene Richardson for laboratory assistance. The authors would also like to thank the patients, physicians, and nurses of Renown Health OB/GYN for their support of our research.

\section{Authorship Contributions}

Participated in research design: Barnett, Buxton.

Conducted experiments: Barnett, Asif, Anderson, Buxton.

Performed data analysis: Barnett, Asif, Buxton.

Wrote or contributed to the writing of the manuscript: Barnett, Buxton.

No author has an actual or perceived conflict of interest with the contents of this article.

\section{References}

Abudara V, Bechberger J, Freitas-Andrade M, De Bock M, Wang N, Bultynck G, Naus CC, Leybaert L, and Giaume C (2014) The connexin43 mimetic peptide Gap19 inhibits hemichannels without altering gap junctional communication in astrocytes. Front Cell Neurosci 8:306.

Ai Z, Fischer A, Spray DC, Brown AMC, and Fishman GI (2000) Wnt-1 regulation of connexin43 in cardiac myocytes. J Clin Invest 105:161-171.

Barnett SD and Buxton ILO (2017) The role of S-nitrosoglutathione reductase (GSNOR) in human disease and therapy. Crit Rev Biochem Mol Biol 52:340-354.
Barnett SD and Buxton ILO (2018) Hiding in plain sight: nebivolol exhibits compelling tocolytic properties. J Cell Mol Med 22:6391-6395.

Barnett SD, Smith CR, Ulrich CC, Baker JE, and Buxton ILO (2018) S-nitrosoglutathione reductase underlies the dysfunctional relaxation to nitric oxide in preterm labor. Sci Rep 8:5614.

Behrman RE and Butler AS (2007) Preterm Birth: Causes, Consequences, and Prevention, National Academies Press.

Boswell-casteel RC, Johnson JM, Duggan KD, Tsutsui Y, and Hays FA (2016) Selectivity of $\mathrm{Cx} 43$ channels is regulated through PKC-dependent phosphorylation. Circ Res 98:57-65.

Bradley KK, Buxton ILOL, Barber JE, McGaw T, and Bradley ME (1998) Nitric oxide relaxes human myometrium by a cGMP-independent mechanism. Am J Physiol 275:C1668-C1673.

Burra S and Jiang JX (2009) Connexin 43 hemichannel opening associated with Prostaglandin $\mathrm{E}(2)$ release is adaptively regulated by mechanical stimulation. Commun Integr Biol 2:239-240.

Buxton IL (2004) Regulation of uterine function: a biochemical conundrum in the regulation of smooth muscle relaxation. Mol Pharmacol 65:1051-1059.

Contreras JE, Sáez JC, Bukauskas FF, and Bennett MVL (2003) Gating and regulation of connexin $43(\mathrm{Cx} 43)$ hemichannels. Proc Natl Acad Sci USA 100 11388-11393.

Dimitrova N, Zamudio JR, Jong RM, Soukup D, Resnick R, Sarma K, Ward AJ, Raj A, Lee J, Sharp PA, et al. (2017) Compartmentalized connexin 43 S-nitrosylation/ denitrosylation regulates heterocellular communication in the vessel wall. PLoS One 32:736-740.

Ek-Vitorín JF, Pontifex TK, and Burt JM (2018) Cx43 channel gating and permeation: multiple phosphorylation-dependent roles of the carboxyl terminus. Int J Mol Sci 19:1-19.

Flenady V, Reinebrant HE, Liley HG, Tambimuttu EG, and Papatsonis DNM (2014) Oxytocin receptor antagonists for inhibiting preterm labour. Cochrane Database Syst Rev:CD004452.

Foster MW, McMahon TJ, and Stamler JS (2003) S-nitrosylation in health and disease. Trends Mol Med 9:160-168.

Granese R, Gitto E, D'Angelo G, Falsaperla R, Corsello G, Amadore D, Calagna G, Fazzolari I, Grasso R, and Triolo O (2019) Preterm birth: seven-year retrospective study in a single centre population. Ital J Pediatr 45:45.

Hansen DB, Braunstein TH, Nielsen MS, and MacAulay N (2014) Distinct permeation profiles of the connexin 30 and 43 hemichannels. FEBS Lett 588:1446-1457.

He X and Chen Q (2016) Reduced expressions of connexin 43 and VEGF in the firsttrimester tissues from women with recurrent pregnancy loss. Reprod Biol Endocrinol 14:46.

Heyman NS, Cowles CL, Barnett SD, Wu YY, Cullison C, Singer CA, Leblanc N, and Buxton ILO (2013) TREK-1 currents in smooth muscle cells from pregnant human myometrium. Am J Physiol Cell Physiol 305:C632-C642.

Jaffrey SR and Snyder SH (2001) The biotin switch method for the detection of S-nitrosylated proteins. Sci STKE 2001:pl1.

King TJ and Lampe PD (2005) Temporal regulation of connexin phosphorylation in embryonic and adult tissues. Biochim Biophys Acta 1719:24-35.

Knijnenburg TA, Vockley JG, Chambwe N, Gibbs DL, Humphries C, Huddleston KC, Klein E, Kothiyal P, Tasseff R, Dhankani V, et al. (2019) Genomic and molecular characterization of preterm birth. Proc Natl Acad Sci USA 116:5819-5827.

Lai PF, Tribe RM, and Johnson MR (2016) Differential impact of acute and prolonged cAMP agonist exposure on protein kinase A activation and human myometrium contractile activity. J Physiol 594:6369-6393.

Lampe PD, TenBroek EM, Burt JM, Kurata WE, Johnson RG, and Lau AF (2000) Phosphorylation of connexin 43 on serine 368 by protein kinase $\mathrm{C}$ regulates gap junctional communication. J Cell Biol 149:1503-1512.

Leithe E, Mesnil M, and Aasen T (2018) The connexin 43 C-terminus: a tail of many tales. Biochim Biophys Acta Biomembr 1860:48-64.

Li H, Liu TF, Lazrak A, Peracchia C, Goldberg GS, Lampe PD, and Johnson RG (1996) Properties and regulation of gap junctional hemichannels in the plasma membranes of cultured cells. J Cell Biol 134:1019-1030.

Liang JY, Wang SM, Chung TH, Yang SH, and Wu JC (2008) Effects of 18glycyrrhetinic acid on serine 368 phosphorylation of connexin43 in rat neonatal cardiomyocytes. Cell Biol Int 32:1371-1379.

Lillo MA, Himelman E, Shirokova N, Xie LH, Fraidenraich D, and Contreras JE (2019) S-nitrosylation of connexin43 hemichannels elicits cardiac stress-induced arrhythmias in Duchenne muscular dystrophy mice. JCI Insight 4:e130091.

Martin JA, Hamilton BE, Ventura SJ, Osterman MJK, and Mathews TJ (2013) Births: Final Data for 2011, CDC, New York.

Miniño AM, Heron MP, and Smith BL (2006) Deaths: preliminary data for 2004. Natl Vital Stat Rep 54:1-49.

Nnamani MC, Plaza S, Romero R, and Wagner GP (2013) Evidence for independent evolution of functional progesterone withdrawal in primates and guinea pigs. Evol Med Public Health 2013:273-288.

Paquette AG, Shynlova O, Kibschull M, Price ND, and Lye SJ; Global Alliance to Prevent Prematurity and Stillbirth Systems Biology of Preterm Birth Team (2018) Comparative analysis of gene expression in maternal peripheral blood and monocytes during spontaneous preterm labor. Am J Obstet Gynecol 218:345.e1-345.e30.

Pereyra S, Sosa C, Bertoni B, and Sapiro R (2019) Transcriptomic analysis of fetal membranes reveals pathways involved in preterm birth. BMC Med Genomics 12 53.

Pierce BT, Calhoun BC, Adolphson KR, Lau AF, and Pierce LM (2002) Connexin 43 expression in normal versus dysfunctional labor. Am J Obstet Gynecol 186: 504-511.

Reidenbach C, Schwinger RHG, Steinritz D, Kehe K, Thiermann H, Klotz T, Sommer F, Bloch W, and Brixius K (2007) Nebivolol induces eNOS activation and NOliberation in murine corpus cavernosum. Life Sci 80:2421-2427.

Retamal MA, Cortés CJ, Reuss L, Bennett MVL, and Sáez JC (2006) S-nitrosylation and permeation through connexin 43 hemichannels in astrocytes: induction by 
oxidant stress and reversal by reducing agents. Proc Natl Acad Sci USA 103: $4475-4480$.

Ribeiro-Rodrigues TM, Martins-Marques T, Morel S, Kwak BR, and Girão H (2017) Role of connexin 43 in different forms of intercellular communication - gap junctions, extracellular vesicles and tunnelling nanotubes. J Cell Sci 130:3619-3630.

Rundell K and Panchal B (2017) Preterm labor: prevention and management. Am Fam Physician 95:366-372.

Söhl G and Willecke K (2004) Gap junctions and the connexin protein family. Cardiovasc Res 62:228-232.

Solan JL and Lampe PD (2014) Specific Cx43 phosphorylation events regulate gap junction turnover in vivo. FEBS Lett 588:1423-1429.

Straub AC, Billaud M, Johnstone SR, Best AK, Yemen S, Dwyer ST, Looft-Wilson R, Lysiak JJ, Gaston B, Palmer L, et al. (2011) Compartmentalized connexin 43 s-nitrosylation/denitrosylation regulates heterocellular communication in the vessel wall. Arterioscler Thromb Vasc Biol 31:399-407.

Ulrich C, Quillici DR, Schegg K, Woolsey R, Nordmeier A, and Buxton ILO (2012) Uterine smooth muscle S-nitrosylproteome in pregnancy. Mol Pharmacol 81: 143-153.

Vanbésien O and Eichner E (1956) Relaxin. BMJ 2:1171.
Verdurmen KMJ, Hulsenboom ADJ, van Laar JOEH, and Oei SG (2017) Effect of tocolytic drugs on fetal heart rate variability: a systematic review. J Matern Fetal Neonatal Med 30:2387-2394.

Vogel JP, Nardin JM, Dowswell T, West HM, and Oladapo OT (2014) Combination of tocolytic agents for inhibiting preterm labour. Cochrane Database Syst Rev: CD006169.

World Health Organization (2015) WHO recommendations on interventions to improve preterm birth outcomes. Geneva, Switzerland. ISBN: 9789241508988 . https://www.who.int/reproductivehealth/publications/maternal_perinatal_health/ preterm-birth-guideline/en/

Yellon SM, Burns AE, See JL, Lechuga TJ, and Kirby MA (2009) Progesterone withdrawal promotes remodeling processes in the nonpregnant mouse cervix. Biol Reprod 81:1-6.

Address correspondence to: Dr. Scott D. Barnett, Department of Pharmacology, University of Nevada Reno, School of Medicine, 1664 N. Virginia St. (MS 318), Reno, NV 89557. E-mail: sdbarnett@med.unr.edu 